\title{
Uncertainties in Estimating Moisture Fluxes over the Intra-Americas Sea
}

\author{
Alberto M. Mestas-NuñeZ \\ Cooperative Institute for Marine and Atmospheric Studies, University of Miami, Miami, Florida \\ ChidONG ZHANG \\ Rosenstiel School of Marine and Atmospheric Science, University of Miami, Miami, Florida \\ DAVID B. ENFIELD \\ NOAA/Atlantic Oceanographic and Meteorological Laboratory, Miami, Florida
}

(Manuscript received 11 November 2004, in final form 3 March 2005)

\begin{abstract}
This study estimates discrepancies in moisture flux divergence in the Intra-Americas Sea (IAS; including the Gulf of Mexico and the Caribbean Sea) calculated using sounding observations, the NCEP Eta highresolution regional analysis, and the NCEP-NCAR coarse-resolution global reanalysis. The main purpose of this exercise is to quantify the uncertainties in the global reanalysis when it is used to calculate annual and interannual variability of moisture flux divergence in the region. An accurate estimate of moisture flux divergence is crucial to evaluate whether the IAS serves as a water vapor source for rainfall over the adjacent land. Using the three datasets, the uncertainties of calculated moisture flux divergence due to the design of the boundary of the area, mathematical algorithms, and spatial and temporal resolutions are quantified. The results show that the large seasonal and interannual variability in moisture flux divergence estimated using the NCEP-NCAR reanalysis is not compromised by these uncertainties. Therefore, NCEPNCAR reanalysis, with its global coverage and long-term record, can be used to provide the best estimate of short climate variability of moisture flux divergence available to date. Further comparisons are made of the moisture flux divergence based on the NCEP-NCAR reanalysis with previous estimates using singleyear sounding observations, as well as with multiyear estimates based on global datasets of surface evaporation and precipitation. It is shown that the previous estimates using single-year sounding observations bear large uncertainties because of interannual variability. Large uncertainties also exist in datasets of surface global evaporation and precipitation.
\end{abstract}

\section{Introduction}

During summer, the region east of the Rocky Mountains receives considerable moisture from the IntraAmericas Sea (IAS), composed of the Gulf of Mexico and the Caribbean Sea (e.g., Rasmusson 1967; Hu and Feng 2001). There are two primary vehicles for the northward transport of IAS moisture: the southerly Great Plains low-level jet (GPLLJ) along the lee (east) side of the Rocky Mountain range and southerly flow of moisture across the Gulf Coast farther east (Higgins et al. 1997; Schubert et al. 1998). Almost one-third of all

Corresponding author address: Alberto Mestas-Nuñez, NOAA/ AOML, 4301 Rickenbacker Causeway, Miami, FL 33149.

E-mail: alberto.mestas@noaa.gov the summer moisture that enters the continental United States is transported by the GPLLJ (Helfand and Schubert 1995). Clearly, land-based factors such as orography, ground moisture, and reevaporation play a critical role in how and where the moisture is precipitated, as does the prevailing synoptic patterns that modulate the northward flow from the IAS (Byerle and Paegle 2003; Anderson et al. 2004). However, little is known about the ultimate source of the moisture itself-the IAS warm pool—and how the warm pool and the moisture budget above affect the availability of summertime moisture over the central United States. Future research aimed at understanding summer precipitation must therefore deal with the IAS moisture budget using recently developed datasets that were unavailable to earlier studies. 


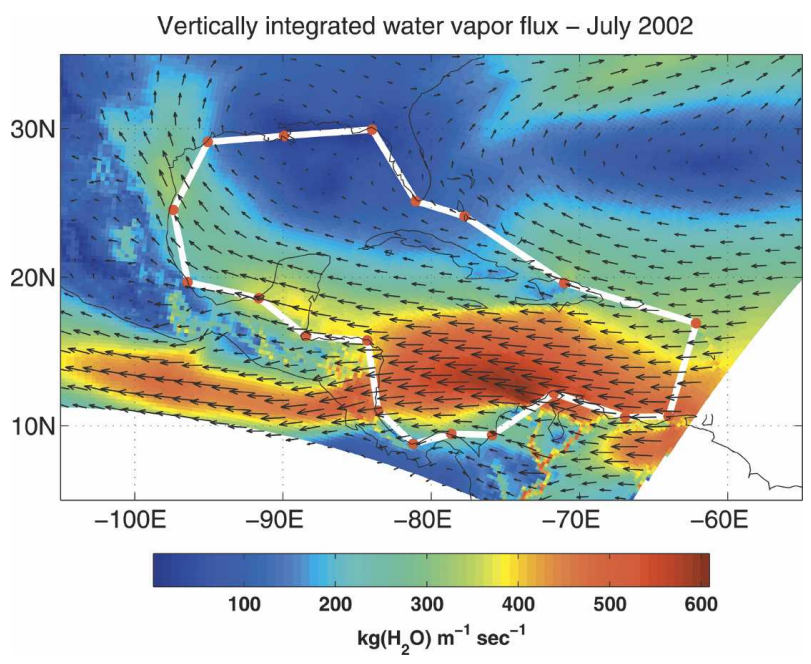

FIG. 1. Mean vertically integrated vapor fluxes calculated from twice-daily Eta analysis fields for Jul 2002. The white solid lines connecting the red dots define boundary $\mathrm{C}$, which along with boundary S (see Fig. 2) are the polygonal boundaries used to estimate the vapor flux divergence in the IAS.

The moisture transported into the central United States comes from different sources, including evaporation from the Gulf of Mexico, the Caribbean Sea, and the tropical Atlantic Ocean east of the Caribbean (Bosilovich and Schubert 2002). In boreal summer, the easterly trade wind carries moisture evaporated from the tropical Atlantic into the Caribbean Sea. There, the trade wind intensifies and forms the Caribbean lowlevel jet (CLLJ). The northern branch of the CLLJ veers northward, crosses over the Yucatan Peninsula, and eventually connects to the GPLLJ (Fig. 1). While the core of the CLLJ and its northern branch are roughly at the $925-\mathrm{hPa}$ level, strong wind speed extends to the surface, which inevitably enhances evaporation and increases the moisture content of the air transported northward.

Hastenrath (1966), using twice-daily soundings of 1960 , estimated the monthly water vapor divergences for the Gulf of Mexico and the Caribbean Sea. Rasmusson $(1967,1968,1971)$ also estimated the annual moisture flux divergences for the Gulf of Mexico and Caribbean Sea using twice-daily sounding data for the 2-yr period May 1961-April 1963. Collectively, they found that the meridional moisture flux into the United States from the IAS undergoes large diurnal and annual cycles and peaks during July-September. Most of the flux takes place below $800 \mathrm{hPa}$ and the maximum is near $950 \mathrm{hPa}$. On an annual average, local surface net evaporation (evaporation minus precipitation) accounts for $25 \%-50 \%(20 \%-25 \%)$ of the total water vapor exported from the Gulf of Mexico (Caribbean Sea) to the west and north. Of the total water vapor exported from the Gulf of Mexico, $58 \%-80 \%$ is to the north into the Great Plains. Of the total water vapor exported from the Caribbean Sea, $12 \%-15 \%$ is to the north into the Gulf of Mexico, which accounts for 51\%$55 \%$ of the total water vapor imported into the Gulf of Mexico.

The pioneering studies of Hastenrath and Rasmusson discussed above first pointed out the importance of the IAS as moisture sources to precipitation in the United States. Their results raised two important questions: How does the moisture budget of the IAS vary interannually? How does the interannual variation in the IAS moisture budget affect the moisture transport into the central United States? While many studies have investigated the relationship between the GPLLJ and precipitation in the central United States, these two questions have yet to be addressed.

The moisture budget of the IAS may vary interannually for a number of reasons. First, it has been shown that precipitation in the IAS region can be modulated by anomalies in sea surface temperature (SST) in both the tropical Pacific and Atlantic Oceans (e.g., Hastenrath 1978; Enfield 1996; Enfield and Alfaro 1999). Second, the IAS is part of the Western Hemisphere warm pool, which is the second largest warm pool in the world (Wang and Enfield 2001, 2003). The interannual fluctuations in the warm-pool size are quite significant, which may affect the amount of moisture that is evaporated from the surface and carried by the low-level jet. Finally, it has been shown that as the warm-pool characteristics vary interannually, so too do the strength of the CLLJ and the stability of the tropospheric air column (Knaff 1997). All of these factors will potentially affect the moisture budget over the IAS through volume divergence, precipitation, and the evaporation of new moisture locally.

Our overall research goal is to explore the connection among the IAS warm pool, its moisture budget, moisture transport from the IAS into North America, and warm-season precipitation over North America. To accomplish this goal a multiyear gridded dataset of wind and moisture is necessary. Such data are available only from model reanalysis, such as the National Centers for Environmental Prediction-National Center for Atmospheric Research (NCEP-NCAR) reanalysis (Kalnay et al. 1996). However, this global reanalysis dataset is subject to possible sources of errors-for example, inadequacies in the data assimilation procedures and model parameterizations, and coarse resolution. Meanwhile, high-resolution regional analysis products covering the IAS region (Black 1994) are available, but their record length is limited. Sounding observations, even if error free, are sparse in space and nonuniform in 
time. Therefore, it is useful to assess the uncertainties of these datasets and establish one or more of them as appropriate for analysis. A suitable approach would be to compare these datasets and quantify the discrepancies among them. The relevant question is whether the uncertainties will be sufficiently large to obscure the annual and interannual signals.

Several possible sources of uncertainty are considered: assimilation of sounding observations, sensitivity to the boundary enclosing the area of interest, algorithms for calculating the moisture budget, and horizontal, vertical, and temporal resolutions. The NCEP Eta high-resolution regional analysis product (Black 1994 ) is used to compare to both the sounding observations and the coarse-resolution NCEP-NCAR global reanalysis for a 2-yr period. Comparisons are also made between the NCEP-NCAR reanalysis and the global reanalysis from the European Centre for MediumRange Weather Forecasts (ECMWF) and two other datasets of moisture budget.

The datasets and methods are described in section 2 . The uncertainty estimates are discussed in section 3 . Section 4 shows the interannual variability of the moisture budget for the IAS based on the NCEP-NCAR reanalysis, which is further compared with other independent estimates of moisture budget in section 5. A summary and discussion are given in section 6 .

\section{Datasets and methods}

\section{a. Datasets}

The main datasets used in this study are twice daily (0000 and 1200 UTC) atmospheric sounding observations, four-times daily (0000, 0600, 1200, and 1800 UTC) Eta regional model analyses (Black 1994), and daily NCEP-NCAR global reanalyses (Kalnay et al. 1996; Kistler et al. 2001).

The atmospheric soundings data come from the array of stations around the IAS shown in Fig. 2. Also shown in Fig. 2 are the Eta analysis grid points, which appear as a shaded area due to the high resolution of the Advanced Weather Information Processing System (AWIPS221) grid (about $32 \mathrm{~km}$ ), and the NCEPNCAR global reanalysis grid points $\left(2.5^{\circ}\right.$ resolution $)$.

Among the different grids on which Eta regional model analyses are available, we chose the AWIPS221 grid because it includes the IAS region. The Eta analysis fields were obtained from NCEP through an automatic ftp procedure that downloaded and archived these fields several times per day from April 2002 through March 2004 (two full years). With the purpose of comparing the Eta analyses with the sounding data, we also downloaded all available Eta Model Output

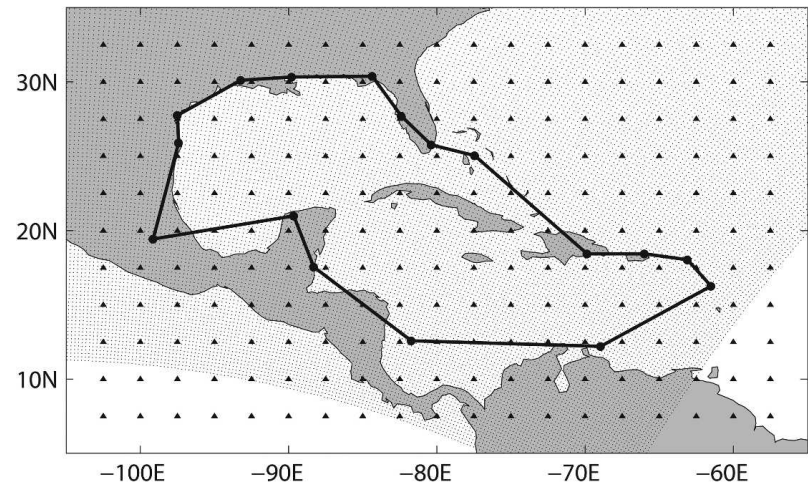

FIG. 2. Boundary S (thick solid line) defined by the sounding stations (black dots) and used to estimate divergences of the water vapor fluxes in the IAS. The gray shading indicates the Eta model grid points (about 32-km resolution), and the black triangles indicate the NCEP-NCAR global reanalysis grid points $\left(2.5^{\circ}\right.$ resolution).

Location Time Series (MOLTS), which are simulated soundings at selected locations in the model domain. The sounding stations of Fig. 2 were selected with the condition that there were MOLTS available at those locations during our analysis period.

The NCEP-NCAR global reanalysis is available online from the National Oceanic and Atmospheric Administration-Cooperative Institute for Research in Environmental Sciences (NOAA-CIRES) Climate Diagnostics Center (CDC) with 6-hourly (0000, 0600, 1200, and 1800 UTC) temporal resolution as well as condensed daily and monthly averaged versions. For practical reasons we decided to use the smaller daily averaged version of the 6-hourly dataset. However, this decision was taken after verifying with the four-times daily Eta dataset that the uncertainties introduced by the loss of temporal resolution were not significant.

In addition, the 15-yr reanalysis from the European Centre for Medium-Range Weather Forecasts for 1979-93 (ERA-15; Gibson et al. 1997) and the Southampton Oceanography Centre (SOC) unconstrained (SHU; Josey et al. 1998) and constrained (SHC; Grist and Josey 2003) 1980-93 climatology of surface moisture budget (evaporation minus precipitation, or $E-P$ ) are also used. The SHU and SHC climatology of $E-P$ were calculated using unconstrained and constrained latent heat fluxes from the SOC climatology that were converted to $E$ using a latent heat of vaporization constant of $2.5 \times 10^{6} \mathrm{~J} \mathrm{~kg}^{-1}$. We also use two estimates of $P$ (with and without numerical model predictions) from the Climate Prediction Center (CPC) Merged Analysis of Precipitation (CMAP; Xie and Arkin 1997). Because we obtained similar results with both CMAP products we only show the one that com- 
bines observations with numerical model predictions. All these datasets overlap for the period 1980-93.

\section{b. Verification of moisture flux divergence calculations}

The moisture budget can be quantified in terms of moisture flux divergence. The area-averaged balance equation for water vapor in equilibrium, also known as the atmospheric branch of the hydrological cycle (Peixoto and Oort 1992) can be written as

$$
\{\operatorname{div} \mathbf{Q}\}=\{E-P\},
$$

where \{\} represents an average over a given area, $\mathbf{Q}$ is the vertically integrated water vapor flux vector, $E$ is evaporation, and $P$ is precipitation. In (1) $\mathbf{Q}$ is calculated from

$$
\mathbf{Q}=\int_{t o p}^{s f c .} q \mathbf{V} \frac{d p}{g},
$$

where $q$ is specific humidity, $\mathbf{V}$ is vector wind velocity, $p$ is pressure, and $g$ is gravity. Using Gauss's theorem on the plane, (1) can also be written as

$$
\frac{1}{A} \oint_{\gamma}(\mathbf{Q} \cdot \mathbf{n}) d \gamma=\{E-P\},
$$

where $A$ is an area enclosed by the curve $\gamma$ and $\mathbf{n}$ is a unit vector perpendicular to this boundary with outward direction. Note that while (1) requires knowledge of $\mathbf{Q}$ everywhere in the interior of the region $A$, (3) only needs values along the boundary $\gamma$.

The line-integral algorithm in (3) can be used to calculate the moisture flux divergence for the sounding data as well as the gridded model (re)analysis fields. Linear interpolation is used to grid the datasets along the boundary at the desired spatial resolution. The area-integral algorithm in (1), which requires estimating the divergence of the moisture fluxes in the interior of the regions, can be used only with the gridded datasets. To estimate the divergence in the interior of the regions using the Eta analysis fields we linearly interpolated them to a square grid of $32-\mathrm{km}$ resolution in latitude and longitude. The line- and area-integral estimates of the vapor flux divergence in the IAS using the full horizontal resolution of the Eta analyses $(32 \mathrm{~km})$ were nearly identical, lending us confidence in our calculations.

\section{c. Quantification of uncertainties}

Our general strategy of quantifying the uncertainties is the following. First, we take moisture flux divergence calculated using the Eta analyses as a benchmark; then

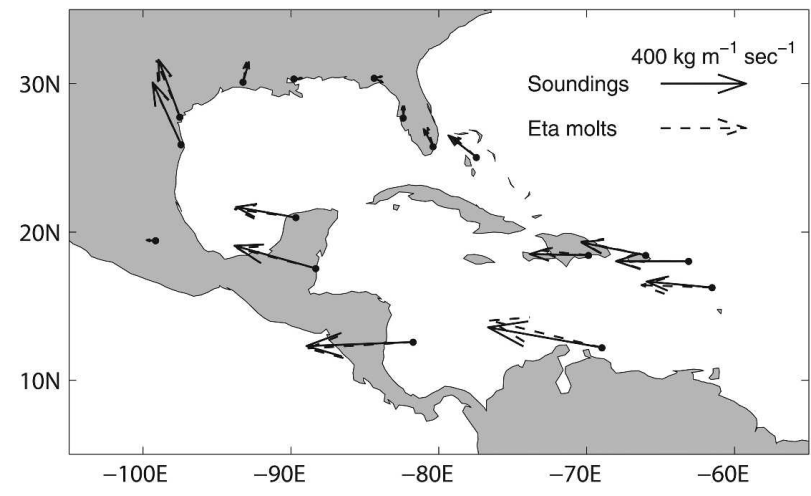

FIG. 3. Vertically integrated water vapor fluxes in the IAS from twice-daily soundings (solid arrows) and Eta molts (dashed arrows) for Jul 2002.

alter either the boundary of the IAS, the algorithm, the resolution of the Eta analyses or their combinations, and recalculate moisture flux divergence; and finally compare the new estimate of moisture flux divergence to the benchmark. The discrepancy between each estimate and the benchmark is taken as a measure of the uncertainty due to the specific parameter(s) altered. This is done for all months through the 2-yr period of April 2002 through March 2004. In particular, the resolutions of the Eta analysis are lowered to the resolutions of the NCEP-NCAR reanalysis to assess possible biases that might have been introduced into the latter by the coarse resolution.

\section{Uncertainty estimates}

The quality of the Eta analyses is first evaluated against the sounding observations. We compute monthly averages of moisture fluxes from soundings and Eta MOLTS for July 2002 at the stations shown in Fig. 2. Our monthly averages are based on twice-daily profiles (0000 and 1200 UTC) of soundings and MOLTS because 6-hourly soundings were not available at all stations. For a given day, if any of the twice-daily sounding profiles are not available at a given station, which happened often in some of the southern stations shown in Fig. 2, then those data are not included in the monthly average of both MOLTS and soundings. The monthly mean fluxes are calculated using twice-daily fluxes and then vertically integrated for both datasets. Their comparison is shown in Fig. 3 for July 2002. The magnitude of the vector difference at each station is in general less than $10 \%$ of the mean magnitude of each vector pair. Exceptions are the two stations of weakest fluxes, Tallahassee $\left(30.4^{\circ} \mathrm{N}, 84.4^{\circ} \mathrm{W}\right)$ and Slidell $\left(30.3^{\circ} \mathrm{N}, 89.8^{\circ} \mathrm{W}\right)$ where the differences are, respectively, $37 \%$ and $50 \%$. The general good agreement between soundings and MOLTS is not surprising, because the soundings were assimilated into the Eta model to 


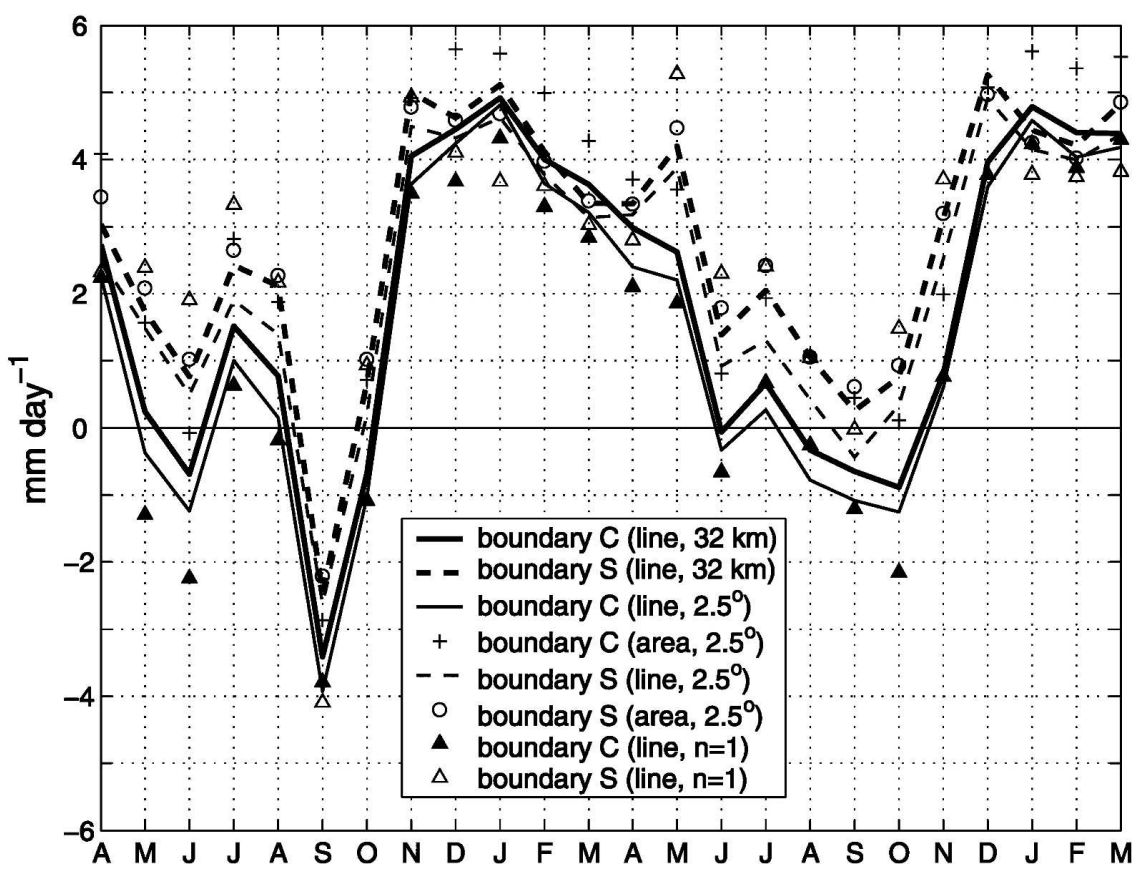

FIG. 4. Comparison of monthly water vapor flux divergence estimates in the IAS using twice-daily Eta analyses for Apr 2002-Mar 2004. Two boundaries C and S are used: C follows roughly the coastlines of the region (Fig. 1), and $\mathrm{S}$ is the polygon defined by the IAS sounding stations used (Fig. 2). The line- and area-integral methods are used with two spatial resolutions $\left(32 \mathrm{~km}\right.$ and $\left.2.5^{\circ}\right)$. The two cases labeled $\mathrm{n}=1$ are based on point observations simulating sounding stations at the vertices of the polygonal boundaries.

produce the Eta analyses and thus they are not independent. Nevertheless, this comparison indicates that biases introduced by data assimilation are not major concerns in this region.

The vertically integrated vapor fluxes are then used to estimate the net divergence of moisture in the region defined by the polygon joining the sounding sites (thick solid line in Fig. 2). We use the line integral in (3) and assume that the fluxes vary linearly between sounding sites. The net divergence of moisture over the IAS estimated from the soundings is $2.4 \mathrm{~mm} \mathrm{day}^{-1}$, which agrees very well with estimates from the Eta MOLTS $\left(2.7 \mathrm{~mm} \mathrm{day}^{-1}\right)$. This means that, neglecting the local storage of water vapor during July 2002 (about $2 \times$ $10^{-4} \mathrm{~mm} \mathrm{day}^{-1}$ ), evaporation in the IAS exceeded precipitation by that amount.

The good agreement between the soundings and the Eta MOLTS justifies using the Eta analysis to produce a benchmark estimate of the moisture fluxes in the IAS. An example of the Eta vertically integrated vapor fluxes for July 2002 is shown in Fig. 1. The arrows in Fig. 1 are vertically integrated water vapor fluxes (for clarity they are displayed at a coarser resolution) with vector magnitudes shown in color.

We have performed multiple estimates of moisture flux divergences in the IAS using the Eta analysis fields with altered boundaries, resolutions, and algorithms, and quantify the uncertainties due to these parameters. Next, we provide a summary and interpretation of these uncertainty estimates.

\section{a. Boundary and horizontal resolution}

The crude representation of the IAS boundary by the polygon connecting the sounding sites shown in Fig. 2 (hereafter boundary S) may introduce biases in calculations of moisture flux divergence. To estimate the uncertainties due to inevitable choices of the IAS boundary, the moisture flux divergence is calculated along an alternative boundary that represents the IAS coastlines more accurately than boundary S (solid white line connecting the red dots in Fig. 1, hereafter boundary C) using the same twice-daily (0000 and 1200 UTC) Eta analysis data for April 2002-March 2004. Both the line- and area-integral algorithms discussed in section $2 \mathrm{~b}$ are used. For the line integral, both the original ( 25 $\mathrm{km}$ ) resolution of the Eta data and a reduced one to match the resolution of the NCEP-NCAR reanalysis $\left(2.5^{\circ}\right)$ are used. The results are summarized in Fig. 4 and Table 1.

For ease of discussion, the estimate of IAS moisture 
flux divergence using the line integral along boundary $\mathrm{C}$ at the full $(32 \mathrm{~km})$ resolution is taken as the reference in this comparison (thick solid line in Fig. 4). For this reference time series, its mean is $1.84 \mathrm{~mm} \mathrm{day}^{-1}$, its standard deviation is $2.35 \mathrm{~mm}^{-1 a y}{ }^{-1}$, and its maximum $\left(4.92 \mathrm{~mm} \mathrm{day}^{-1}\right)$ to minimum $\left(-3.41 \mathrm{~mm} \mathrm{day}^{-1}\right)$ range is $8.33 \mathrm{~mm} \mathrm{day}^{-1}$. The estimates of moisture flux divergence based on line (thick solid line) integrals along boundary $\mathrm{C}$ and area integrals over its enclosed area (not shown) are nearly identical at the $32-\mathrm{km}$ resolution, with their mean difference of $0.13 \mathrm{~mm} \mathrm{day}^{-1}$ and rms difference $0.19 \mathrm{~mm}$ day $^{-1}$. The line-integral estimates for boundary S (thick dashed lines in Fig. 4) deviate more from the reference (mean difference 0.88 $\mathrm{mm}$ day $^{-1}$, rms difference $1.12 \mathrm{~mm} \mathrm{day}^{-1}$ ), but are identical to the area-integral estimates for the area enclosed by boundary S (not shown). The other curves in Fig. 4 are the line and area estimates for the two boundaries but using a resolution of $2.5^{\circ}$. At the coarser resolution, the line-integral method has both smaller bias $(-0.39)$ and smaller rms difference (0.41). The larger bias (1.02) corresponds to the area estimate for boundary C (plus symbols). The larger rms difference (1.29) corresponds to the area estimate with boundary $S$ (open circles), but this difference is comparable to the line and area estimates for boundary $\mathrm{S}$ at $32-\mathrm{km}$ resolution. These comparisons indicate that larger uncertainties ( $\mathrm{rms} \geq 1 \mathrm{~mm} \mathrm{day}^{-1}$ ) can be introduced by the choice of the boundary, and the line-integral approach is more accurate than the area integral at the coarser resolution.

The uncertainties due to horizontal resolution can be evaluated to an extreme: No data are made available except at certain points, as in the case of sounding observations. In line-integral estimates of moisture flux divergence, linear interpolations between two adjacent sounding sites, instead of gridded data along the line, must be used. Such "point estimates" were made using the sounding sites along boundary S (Fig. 2) and the arbitrary points along boundary C (Fig. 1). In Fig. 4, they are compared with the estimates using the fullresolution data. The mean and rms differences between the full-resolution (thick solid) and point estimates (solid triangles) for boundary $\mathrm{C}$ are -0.62 and $0.75 \mathrm{~mm}$ day $^{-1}$, respectively (Table 1 ). The respective values for boundary $\mathrm{S}$ (thick dashed and open triangles) are -0.02 and $0.77 \mathrm{~mm} \mathrm{day}^{-1}$ (not included in Table 1 ). The conclusion is that uncertainties introduced by using point observations are smaller than that due to the choice of boundary. In other words, uncertainties in any estimates of moisture flux divergence using sounding observations are mainly from the crude boundary lines
TABLE 1. Mean and rms difference in $\mathrm{mm} \mathrm{day}^{-1}$ of Eta moisture flux divergence estimates in the IAS using as a reference the line-integral estimate on boundary $\mathrm{C}$ at $32-\mathrm{km}$ resolution from twice-daily Eta fields (thick solid line in Fig. 4). The mean and standard deviation of the reference time series are 1.84 and 2.35 $\mathrm{mm}$ day $^{-1}$, respectively.

\begin{tabular}{lcc}
\hline \hline & $\begin{array}{c}\text { Mean } \\
\text { difference }\end{array}$ & $\begin{array}{c}\text { Rms } \\
\text { difference }\end{array}$ \\
\hline C, area, 32 km, twice-daily & 0.13 & 0.19 \\
S, line, 32 km, twice-daily & 0.88 & 1.12 \\
S, area, 32 km, twice-daily & 0.94 & 1.19 \\
C, line, $2.5^{\circ}$, twice-daily & -0.39 & 0.41 \\
C, area, $2.5^{\circ}$, twice-daily & 1.02 & 1.05 \\
S, line, 2.5 , twice-daily & 0.46 & 0.79 \\
S, area, $2.5^{\circ}$, twice-daily & 0.98 & 1.29 \\
C, line, $n=1$, twice-daily & -0.62 & 0.75 \\
C, line, 32 km, 6-hourly & 0.11 & 0.26 \\
C, line, 32 km, daily & -0.04 & 0.29 \\
C, line, 32 km, twice-daily, & 0.05 & 0.11 \\
coarse vertical & & \\
\hline
\end{tabular}

that are dictated by the limited number of sounding sites (as shown in Fig. 2).

\section{b. Temporal resolution}

It has long been known that the moisture flux from the IAS undergoes substantial diurnal cycle (e.g., Rasmusson 1967). This begs the question, What would be the bias in moisture flux divergence estimated using data that do not fully resolve the diurnal cycle? This question is particularly germane to using daily data of the NCEP-NCAR reanalysis to estimate moisture flux divergence for the IAS. To address this question, monthly mean moisture flux divergences for the IAS were calculated using 6-hourly, twice-daily, and daily vertically integrated moisture fluxes from the Eta regional analyses using the line integral along boundary C. The twice-daily resolution is obtained by considering only the 0000 and 1200 UTC fields. To obtain the daily resolution we first compute the daily averaged zonal and meridional winds and humidity from the 6-hourly fields and then use these daily averages to compute the fluxes before the monthly averaging. Very similar results are obtained regardless of the temporal resolution (Table 1). This indicates that the moisture flux divergence estimates are not very sensitive to the use of 6-hourly twice-daily, or daily resolutions. It is worth noting that our results do not imply that the diurnal cycle is not important. Rather they suggest that if fully resolving the diurnal cycle is important to monthly mean moisture flux divergence, the temporal resolution required must be higher than four times per day. 


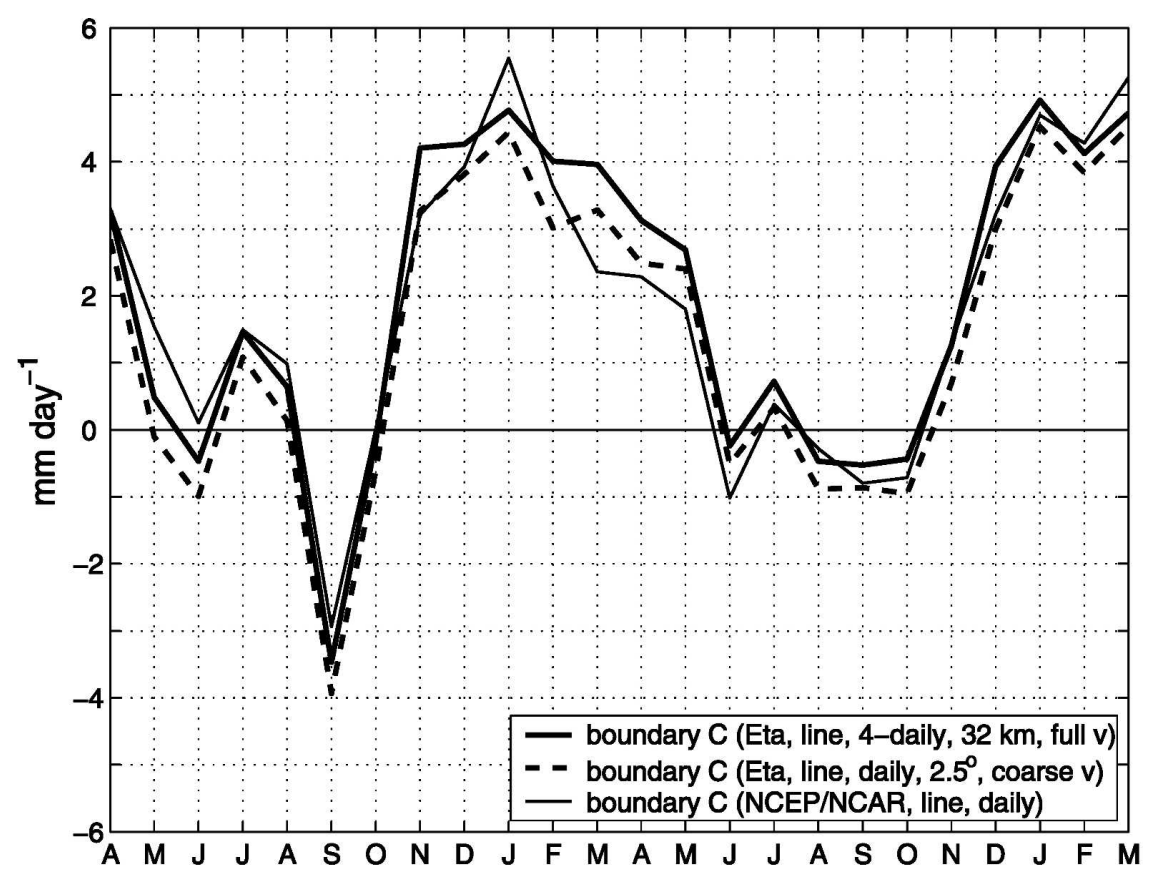

FIG. 5. As in Fig. 4 but using line-integral estimates with full-resolution Eta analysis (thick solid), coarse-resolution Eta analysis (thick dashed), and daily NCEP-NCAR reanalysis (thin solid).

\section{c. Vertical resolution}

The Eta analyses have a vertical resolution of $25 \mathrm{hPa}$ and extend from 1000 to $50 \mathrm{hPa}$. Data with this full vertical resolution are used in all previously discussed estimates of vertically integrated moisture flux divergence. The NCEP-NCAR global reanalyses are normally available at the standard pressure levels of 300 , 400, 500, 600, 700, 850, 925, and $1000 \mathrm{hPa}$. Possible uncertainties in estimates of moisture flux divergence introduced by this coarser vertical resolution need to be quantified. To do this, the twice-daily Eta analysis fields were interpolated to the same coarse resolution as the NCEP-NCAR reanalysis and then used to estimate moisture flux divergence using the line integral along boundary C. Very similar results are obtained with the full and coarse vertical resolutions (Table 1). This indicates that the coarse vertical resolution of the NCEPNCAR reanalysis should not be a significant source of uncertainties in estimates of moisture flux divergence.

\section{d. Combined uncertainties}

In the previous sections, we examine the separate effects of coarse horizontal, vertical, and temporal resolutions on estimating moisture flux divergence in the IAS. Now we examine their combined effects. We used the Eta analysis to make two estimates that are compared in Fig. 5; one with its full resolutions and the other with resolutions all reduced to those of the daily
NCEP-NCAR reanalysis. The line integral along the more realistic boundary $\mathrm{C}$ was used in both cases. The mean and rms differences (coarse minus full resolution) are -0.5 and $\pm 0.54 \mathrm{~mm}^{-1 a y}{ }^{-1}$, respectively. For comparison, we also show the moisture divergence estimates from the actual NCEP-NCAR reanalysis (thin solid line).

The mean and rms differences between the global daily NCEP-NCAR reanalysis and the full-resolution Eta estimates are -0.13 and $\pm 0.63 \mathrm{~mm} \mathrm{day}^{-1}$. The uncertainties due to the coarser resolutions of the global reanalysis are much smaller than the peak-to-peak range of seasonal variability (about $8 \mathrm{~mm} \mathrm{day}^{-1}$ ) seen in Figs. 4 and 5. This gives our final evaluation of the usefulness of the global daily NCEP-NCAR reanalysis in estimating the interannual variability of moisture flux divergence in the IAS: the annual and interannual variability of moisture flux divergence in the IAS is sufficiently large that they are not compromised by the small uncertainties due to factors considered here. We therefore can use with confidence the long record of the global daily NCEP-NCAR reanalysis to address the role of the IAS in the annual variability of moisture transport into the central United States and precipitation there.

\section{Interannual variability}

There has been hardly any other estimate of the water vapor budget for the IAS using sounding observa- 


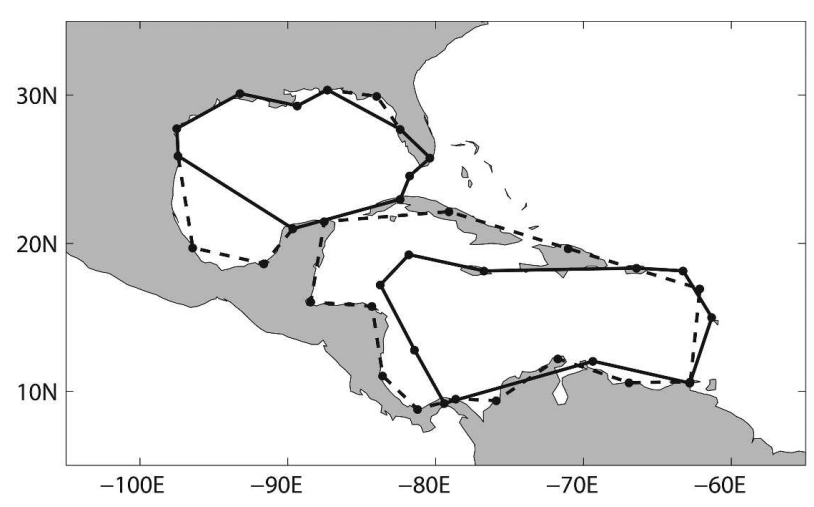

FIG. 6. Map of stations used for calculating the moisture flux divergence in the Gulf of Mexico and Caribbean Sea. The thick solid lines are the boundaries of Hastenrath (1966), and the dashed lines are our adaptations to follow more closely the continental boundaries.

tions since the pioneering studies of Hastenrath (1966) and Rasmusson (1967, 1968, 1971). Their detailed quantitative results are of great value to the study of the climatic role of the IAS. But it is unknown whether and how much their results based on single-year data are possibly obscured by the interannual variability of the region. To address this possibility, we try to replicate their results using the daily NCEP-NCAR global reanalysis for the same years of their sounding observations. We use the line integral to calculate the moisture flux divergence separately for the Gulf of Mexico and Caribbean Sea as Hastenrath (1966) did for 1960 and as Rasmusson (1967) did for 1961-63. In the Gulf of Mexico and Caribbean Sea, uncertainties due to the Hastenrath (1966) boundaries instead of boundaries that are more realistic (Fig. 6) and due to point data instead of the gridded data are both smaller than the peak-to-peak range of seasonal variability (about 10 $\mathrm{mm}$ day $^{-1}$ ). Therefore, the Hastenrath boundaries are used in calculations of the interannual variability of moisture flux divergence, so the results of Hastenrath (1966) and Rasmusson $(1967,1968,1971)$ can be evaluated in the context of the climatological annual cycle and interannual variability (Fig. 7).

The range of interannual variability is represented by the \pm two standard deviation envelope about the mean (thick dashed lines in Fig. 7), which is about $\pm 2 \mathrm{~mm}$ day $^{-1}$ corresponding closely with the maximum range of interannual variability (thin dashed lines in Fig. 7). An exception is September in the Gulf due to an anomalous minimum in 1998 that may be associated with larger than normal precipitation due to Hurricane Georges, which crossed the Gulf of Mexico during the last week of September 1998 and made landfall near Biloxi, Mississippi.
The long-term mean seasonal cycle (thick solid lines in Fig. 7) shows that the IAS as a whole is a source of moisture during October-August with a maximum in February and a sink during August-October with a minimum in September (Fig. 7a). The Gulf of Mexico (Fig. 7b) is a source of moisture year-round with a minimum in September and a maximum in November. The Caribbean is a source during December-July with a maximum in March and a sink the rest of the year with a minimum in October (Fig. 7c).

The Hastenrath (1966) estimates of the 1960 moisture divergences for the Gulf and Caribbean, shown with open squares in Figs. $7 \mathrm{~b}$ and $7 \mathrm{c}$, are most of the time within the range of interannual variability and close to the estimate for 1960 using the NCEP-NCAR reanalysis (solid triangles in Figs. $7 \mathrm{~b}$ and $7 \mathrm{c}$ ). In some months, such as April in the Gulf and January in the Caribbean, the differences are quite large and the Hastenrath estimates are beyond the interannual variability range.

Rasmusson (1968) estimated annual mean moisture flux divergences in the Gulf and Caribbean for two years-May 1961-April 1962 and May 1962-April 1963 - using slightly different boundaries. We averaged these two values and used the same areas of Hastenrath's regions to obtain the values shown with open circles on the right $y$ axes of Figs. 7b and 7c. For comparison, we averaged the NCEP-NCAR estimates for the same 2-yr period and show the values with open triangles on the same axes. The NCEP-NCAR mean moisture flux divergences over the entire 1960-2003 period for the three regions are shown with thick solid tick marks on the right $y$ axes of Fig. 7. In the Gulf, the estimates from Rasmusson and NCEP-NCAR are similar and only slightly larger than the long-term mean. In the Caribbean, the NCEP-NCAR estimate for the Rasmusson period coincides with the long-term mean, and Rasmusson (1968) estimates appear to be too large.

All the comparisons discussed in this section suggest that estimates of moisture flux divergence based on data from a single year or a short period may not accurately reflect the climatology. This is not a surprising result.

\section{Comparisons with other $\boldsymbol{E}-\boldsymbol{P}$ estimates}

Following the water budget equation in equilibrium (1), the moisture flux divergence in a given region should balance the difference of evaporation minus precipitation $(E-P)$ averaged over the region. To further explore the uncertainties, our estimates of the seasonal cycle of moisture flux divergence, for the IAS, Gulf of Mexico, and Caribbean using the global NCEP- 

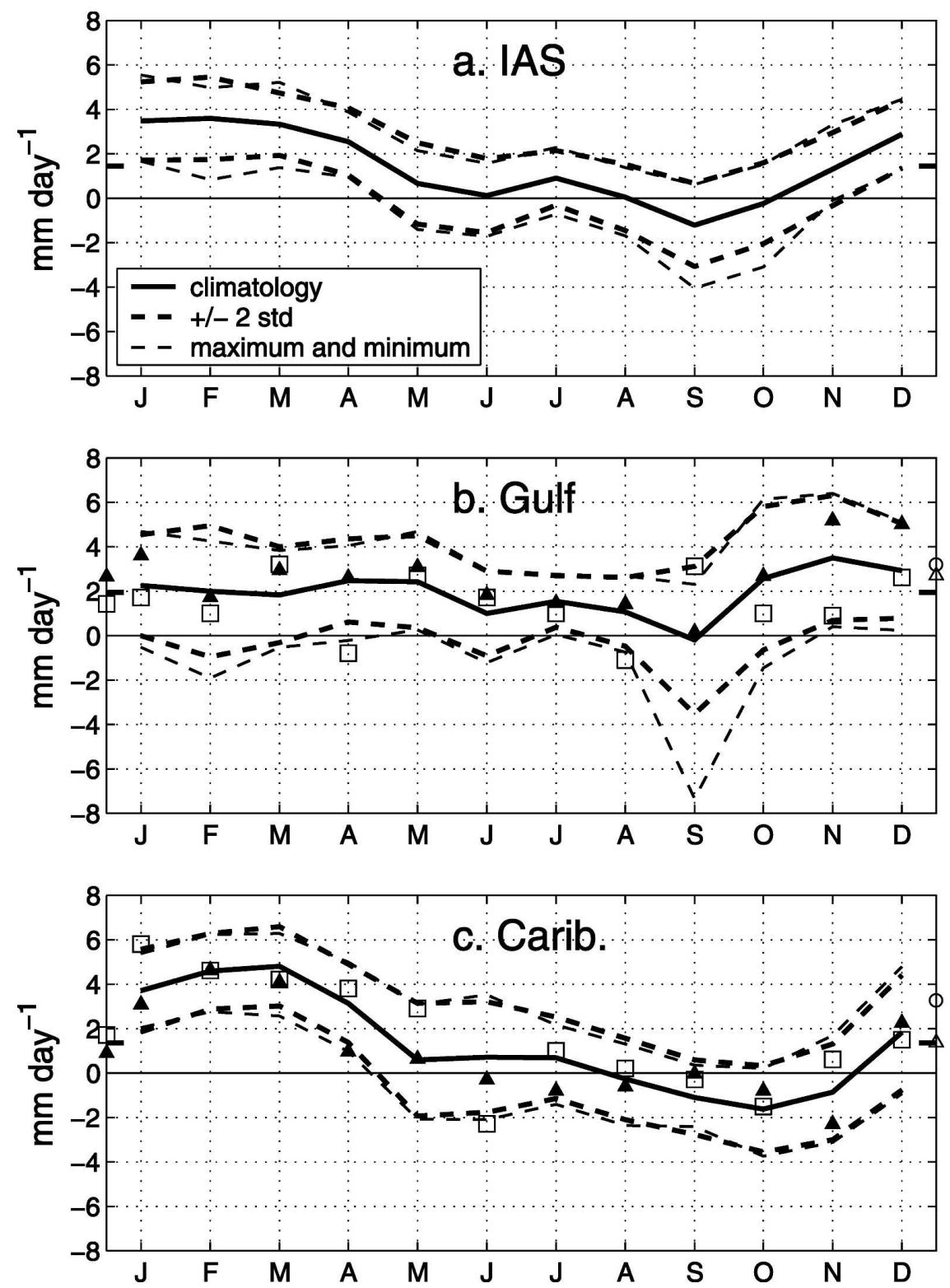

FIG. 7. Long-term mean seasonal cycle (1960-2003) of the monthly moisture flux divergence calculated from the global NCEP-NCAR daily reanalysis: (a) in the IAS, (b) in the Gulf of Mexico, and (c) in the Caribbean Sea (see Fig. 6). The thick dashes indicate the \pm 2 std dev range and the thin dashes the maximum-minimum range of interannual variability. The open squares (solid triangles) are the Hastenrath (NCEP-NCAR reanalysis) 1960 values. The annual mean NCEP-NCAR divergences for 1960-2003 are shown with thick solid tick marks on both left and right $y$ axes. In the left $y$ axes, the open squares (solid triangles) are the Hastenrath (NCEP-NCAR) 1960 annual means. In the right $y$ axes, the open circles (open triangles) are the Rasmusson (NCEP-NCAR) annual mean divergences for May 1962-Apr 1963.

NCAR reanalysis, were compared with climatological estimates of $E-P$ averaged over those regions. These $E-P$ climatological means are based on combining $E$ and $P$ from different sources (see section 2a) for the period 1980-93. The comparisons are shown in Fig. 8.
The estimates of moisture flux divergence using NCEP-NCAR in Fig. 8 (thick solid lines) compare well with the $E-P$ means from the ERA-15 (thin solid) and SHU (thin dashed joining open circles) climatology, with better comparisons in the IAS than in the separate 

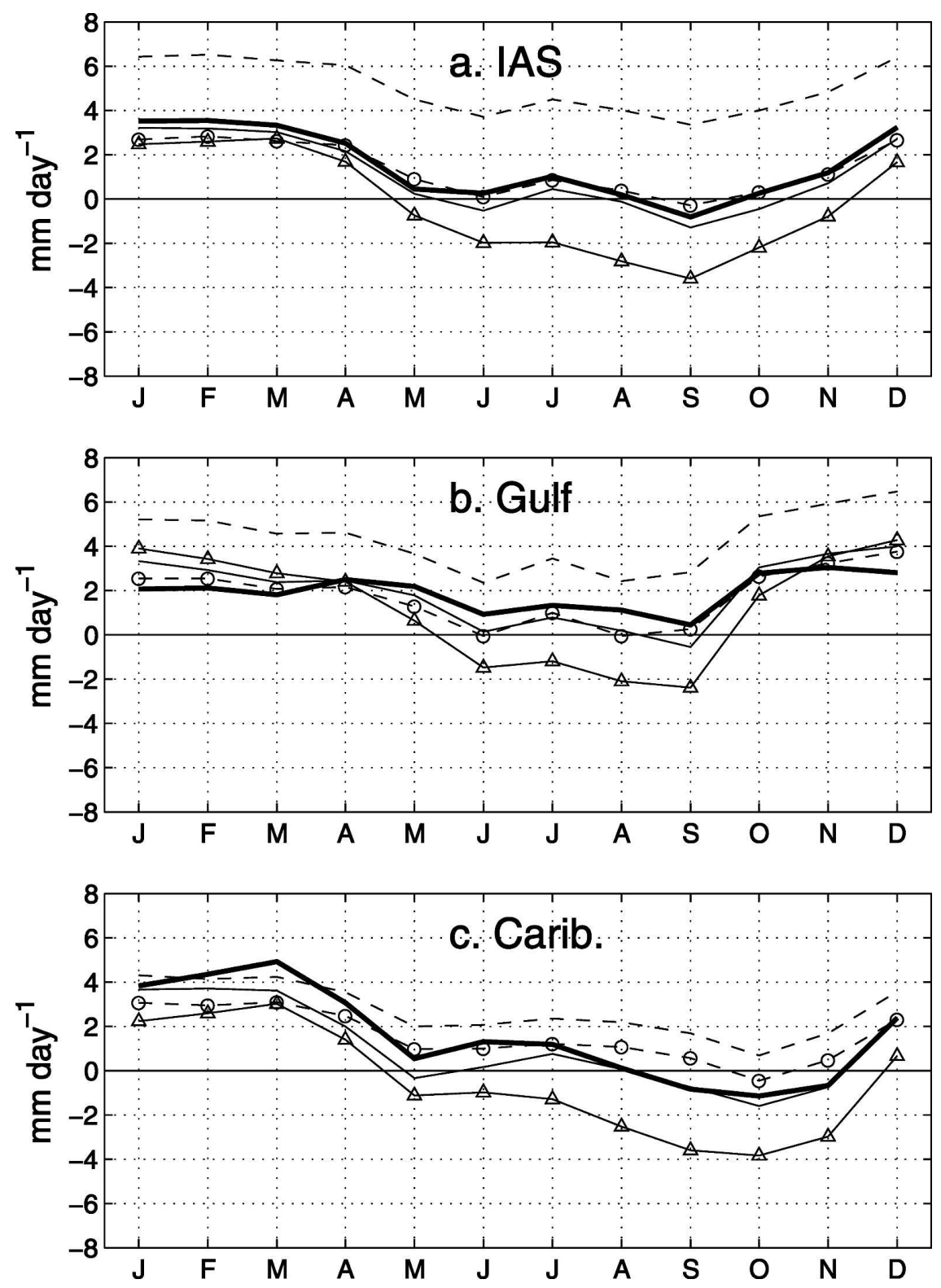

FIG. 8. Comparison of the 1980-93 seasonal cycle of moisture flux divergence from NCEPNCAR global reanalysis (thick solid) and $E-P$ climatologies from ERA-15 (thin solid), SHU (thin dashed joining open circles), SHC (thin dashed), and NCEP-NCAR reanalysis (thin solid joining open triangles) in (a) the IAS, (b) Gulf of Mexico, and (c) Caribbean Sea.

Gulf and Caribbean regions. Except in the Caribbean Sea during February-March, the SHC mean $E-P$ values (thin dashed) are larger than those other three products with extreme differences in the IAS exceeding $2 \mathrm{~mm}$ day $^{-1}$ year-round. The $E-P$ values from the NCEP-NCAR reanalysis (thin solid line joining open triangles) are generally biased low compared to the NCEP-NCAR moisture flux divergences, particularly from May to November when the bias can exceed $2 \mathrm{~mm}$ day $^{-1}$. This shows that the NCEP-NCAR reanalysis is not able to close the water budget in those regions, as was also found in the Baltic Sea (Ruprecht and Kahl 2003).

To investigate the source of the $E-P$ differences in our three study areas, we compared the separate contributions of $E$ and $P$ in Figs. 9 and 10, respectively. In the $E$ comparisons (Fig. 9), we also show an indirect estimate of $E$ based on adding an independent estimate of $P$ (from CMAP, shown in Fig. 10) to the NCEPNCAR moisture flux divergences (thick dashed lines). 

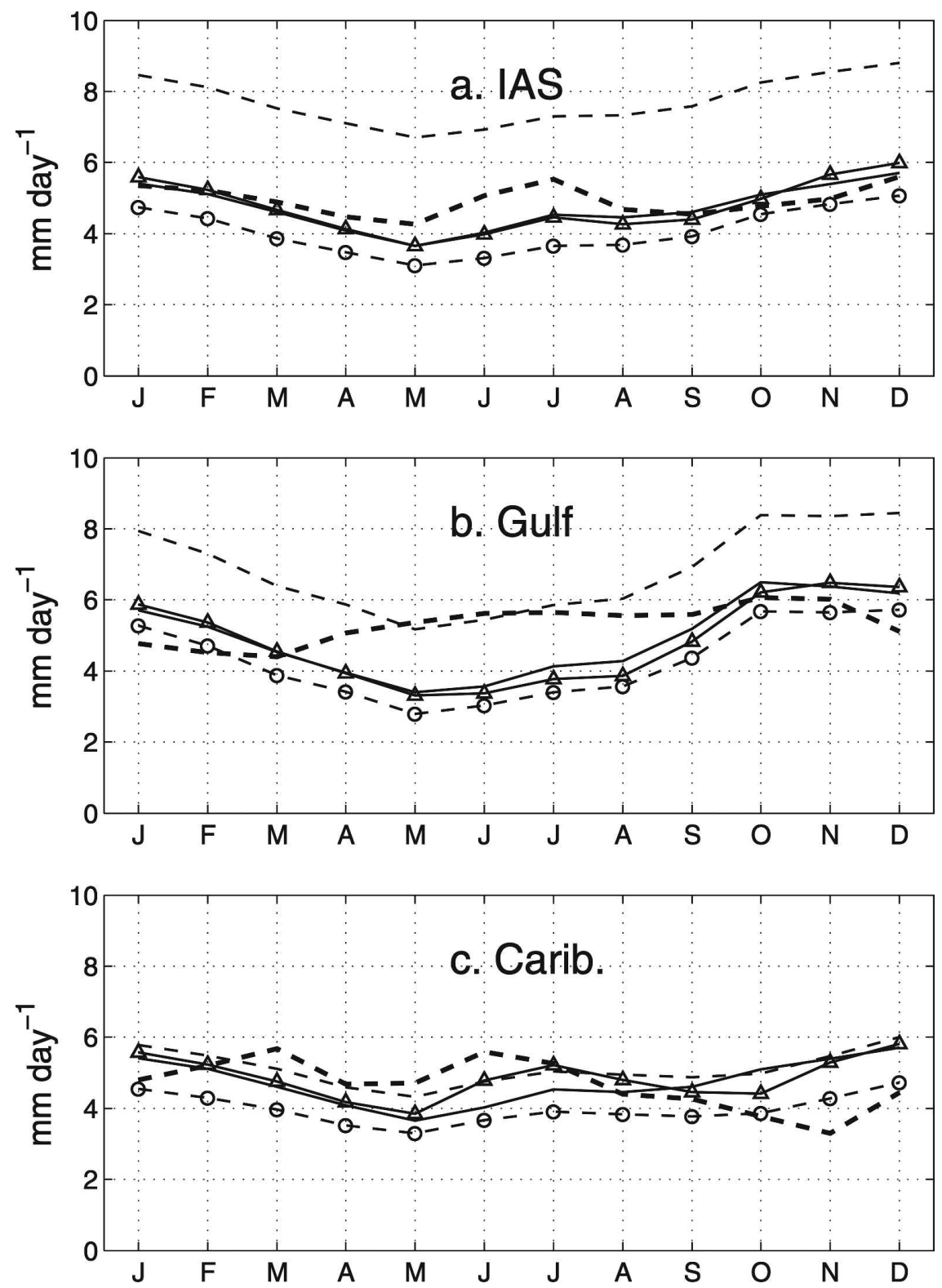

FIG. 9. Comparison of 1980-93 evaporation climatologies from ERA-15 (thin solid), SHU (dashed with open circles), SHC (thin dashed), NCEP-NCAR reanalysis (thin solid joining open triangles), and the sum of NCEP-NCAR moisture flux divergence and CMAP $P$ (thick dashed) in (a) the IAS, (b) Gulf of Mexico, and (c) Caribbean Sea.

In the three regions and apart from the indirect estimate of $E, E$ is larger in the boreal winter months (Fig. 9 ) and $P$ is larger in the boreal summer and fall (Fig. 10), as expected. In the $E$ comparisons (Fig. 9), the SHC estimates of $E$ are usually too large, particularly in the IAS (more than $2 \mathrm{~mm}$ day $^{-1}$ ). The ERA-15, NCEP-NCAR, and SHU $E$ are similar (differences generally smaller than $1 \mathrm{~mm}$ day $^{-1}$ ) with ERA- 15 and NCEP-NCAR being slightly higher than SHU in the three regions year-round. The indirect estimate of $E$, however, behaves differently than the other estimates showing large boreal summer values, but this may just reflect problems with the CMAP estimates.

In the $P$ comparisons of SOC and ERA-15 (Fig. 10), we include an estimate of $P$ from CMAP (section 2a). The NCEP-NCAR $P$ is nearly always too large, particularly during the summer season, which appears to be related to spinup/down problems (e.g., Kanamitsu et al. 2002). The differences between the other $P$ products are generally smaller than $2 \mathrm{~mm} \mathrm{day}{ }^{-1}$ in the three 

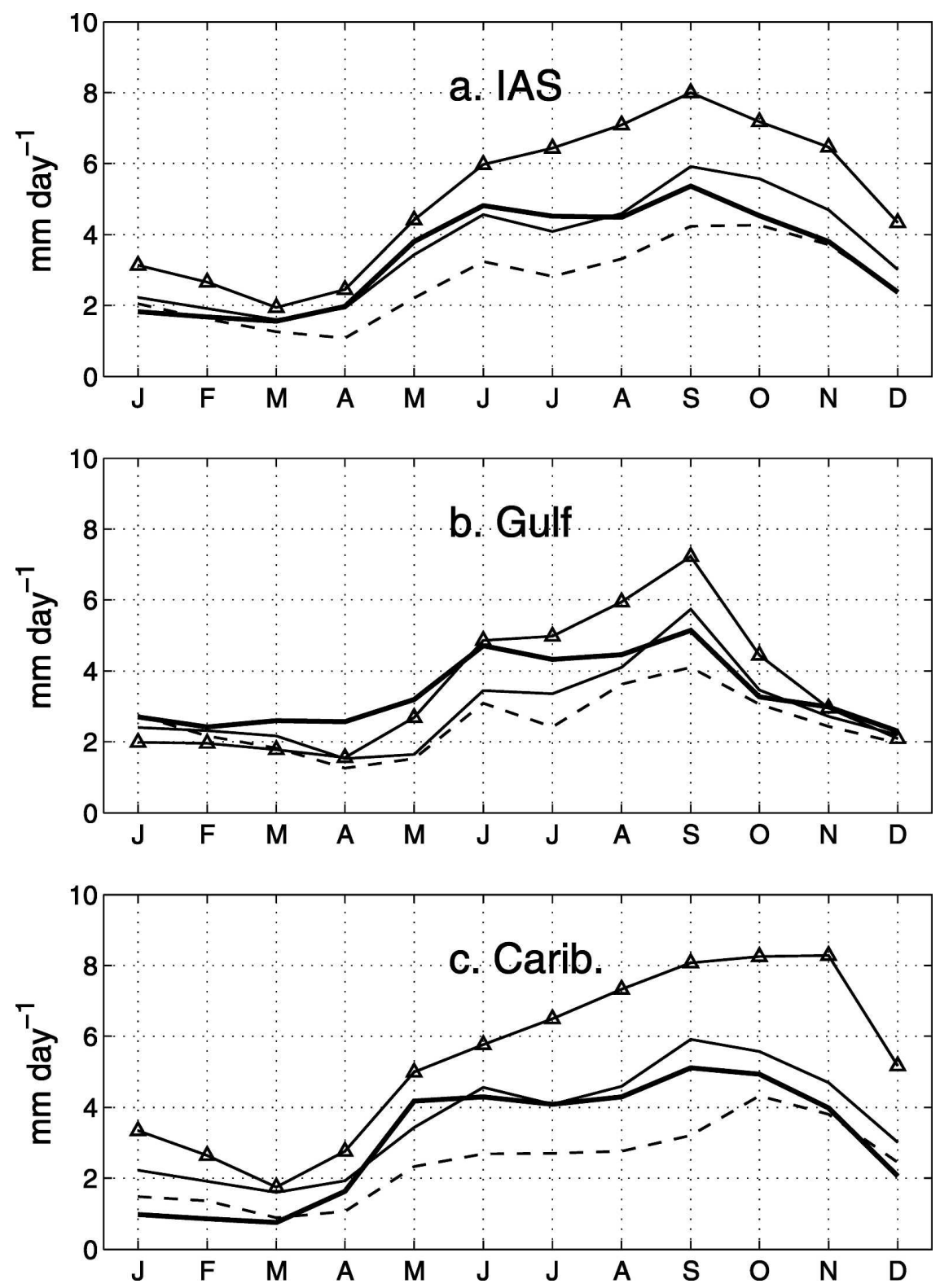

FIG. 10. Comparison of 1980-93 precipitation climatologies based on CMAP data-andmodel fields (thick solid), ERA-15 (thin solid), SOC (thin dashed), and NCEP-NCAR reanalysis (thin solid joining open triangles) in (a) the IAS, (b) Gulf of Mexico, and (c) Caribbean Sea.

regions. The largest discrepancies are in the IAS and the Caribbean, where the SOC $P$ is smaller than the other two by $1-2 \mathrm{~mm} \mathrm{day}^{-1}$ from April to October. The large discrepancies between SHC $E-P$ and the other datasets in Fig. 8 are therefore a result of discrepancies in both $E$ and $P$ of this product.

The general agreement among the mean values of NCEP-NCAR moisture flux divergences and $E-P$ from ERA-15 and SHU lends more confidence on using these datasets in the study of the global hydrological cycle. Meanwhile, the large discrepancies between the SHC and NCEP-NCAR $E-P$ means and the others suggest that we still face large uncertainties in estimating the water vapor budget using data of evaporation and precipitation.

\section{Summary and discussion}

When studying the water vapor budget in the IntraAmericas Sea (IAS) region and its role in the interan- 
nual variability of rainfall in the adjacent areas such as the central United States, it is natural to choose the NCEP-NCAR global reanalysis as the main dataset because of its long record. The accuracy of this dataset in describing the hydrological cycle in the IAS region is, however, difficult to assess. Because of known error sources in sounding observations (e.g., Elliott and Gaffen 1991) and in models, we can hardly choose one dataset as the best. The error characteristics in available datasets for the study of water vapor budgets can be better quantified in terms of uncertainties, defined as discrepancies among those datasets.

In this study, uncertainties in estimated water vapor budget for the IAS region have been quantified using sounding observations, NCEP Eta regional analysis, NCEP-NCAR global reanalysis, ECMWF global reanalysis, two products of $E-P$ from the Southampton Oceanography Centre, and results from Hastenrath (1966) and Rasmusson (1967, 1968, 1971). Special attention has been paid to possible sources of uncertainties from the choices of area boundaries, calculation algorithms, spatial and temporal resolutions, and their combinations. A summary of the main results from this study and their discussions are given below.

1) Among the possible error sources, such as boundaries (defined by sounding sites or coastal lines), algorithms (line versus area integral), and spatial resolutions $\left(2.5^{\circ}\right.$ or higher $)$, uncertainties due to the design of the boundary are the largest and are about $1 \mathrm{~mm}$ day $^{-1}$. In comparison, the peak-to-peak range of the interannual variability as detected from the data used is about $8 \mathrm{~mm}$ day $^{-1}$. Detections of large interannual anomalies are therefore not compromised by any of these uncertainties (Figs. 4 and 5). This lends confidence to using the coarse-resolution NCEP-NCAR global reanalysis as a tool in the study of the water vapor budget of the IAS region and its role in the interannual variability in the adjacent region, such as the central United States. In particular, a combination of the water vapor budget from the NCEP-NCAR reanalysis and an independent data of precipitation would provide an alternative estimate of surface evaporation, which can be useful to study the role of the variability of evaporation in moisture budget of the IAS. An example of this was presented using CMAP, but other datasets should be explored.

2) If fully resolving the diurnal cycle is crucial to an accurate estimate of monthly mean water vapor budget for the IAS region, a temporal resolution higher than $6 \mathrm{~h}$ might be needed. This remains an unsettled issue and it is critical to the use of the NCEP-NCAR reanalysis because of its 6-hourly temporal resolution.

3) Estimates based on data of a single year or a short period (e.g., Hastenrath 1966; Rasmusson 1967, 1968, 1971) may not accurately reflect the climatology of the water vapor budget in the IAS region because of the large interannual variability (Fig. 7), which is hardly surprising but has never been shown before.

4) The water vapor budget for the IAS region based on three datasets (NCEP-NCAR reanalysis, ERA-15 reanalysis, SOC unconstrained $E-P$ product) agree with each other well in the climatological annual cycle (Fig. 8), providing further confidence to the quality of these datasets. However, the large discrepancies between the SOC constrained (SHC) and the NCEP-NCAR $E-P$ products and the others (Figs. 8-10) suggest large uncertainties in estimating the water vapor budget using data of evaporation and precipitation alone. It is worth pointing out that recent studies favored the net SHC surface heat fluxes over other climatological datasets (including SHU and ERA-15) based on an oceanic heat budget of the Western Hemisphere warm pool (Enfield and Lee 2005; Lee et al. 2005). This further highlights the complexity of the issue regarding the data accuracy over open oceans where no "ground truth" can be easily identified. Further studies on this issue are therefore highly warranted.

5) In general, the moisture fluxes are divergent (evaporation exceeds precipitation), indicating that the IAS is a moisture source. As shown in Fig. 1, moisture surplus is exported mainly to the west and to the north. A partition of moisture export from the IAS along these two routes needs to be made, as done by Hastenrath (1966) but in the context of interannual variability. The reason for the interannual variability of the water vapor budget in the IAS region needs to be further explored in terms of the variability of evaporation and precipitation, which may be controlled by remote as well as local factors. Among others, the import of water vapor from the tropical Atlantic as well as of dry air from Saharan air layer outbreaks, the surface wind component of the low-level jet, and the SST of the IAS must be considered.

In conclusion, the results of this study pave the road for using the global NCEP-NCAR reanalysis moisture fluxes in the study of interannual variability in the water budget of the IAS, its relationship to the variability of Western Hemisphere warm pool, and its role in pre- 
cipitation over North America and other areas adjacent to the IAS.

Acknowledgments. We are thankful to NCEP for making the Eta regional analysis dataset available to us through ftpprd.ncep.noaa.gov, the NOAA-CIRES Climate Diagnostics Center for providing the NCEP reanalysis dataset through www.cdc.noaa.gov, Jay Harris for data handling and archiving, Keith Brill for help with the MOLTS, Sang-Ki Lee for assistance with the surface flux datasets, and Hugo Berbery for helpful discussions. We also thank Robert Kistler and an anonymous reviewer for their comments on the manuscript. Financial support was provided by grants from NOAA (through PACS and GAPP). This research was carried out in part under the auspices of the Cooperative Institute for Marine and Atmospheric Studies (CIMAS), a joint institute of the University of Miami and NOAA, Cooperative Agreement NA17RJ1226.

\section{REFERENCES}

Anderson, B. T., H. Kanamaru, and J. O. Roads, 2004: The summertime atmospheric hydrologic cycle over the southwestern United States. J. Hydrometeor., 5, 679-692.

Black, T. L., 1994: The new NMC mesoscale Eta model: Description and forecast examples. Wea. Forecasting, 9, 265-278.

Bosilovich, M. G., and S. D. Schubert, 2002: Water vapor tracers as diagnostics of the regional hydrologic cycle. J. Hydrometeor., 3, 149-165.

Byerle, L. A., and J. Paegle, 2003: Modulation of the Great Plains low-level jet and moisture transports by orography and largescale circulations. J. Geophys. Res., 108, 8611, doi:10.1029/ 2002JD003005.

Elliott, W. P., and D. J. Gaffen, 1991: On the utility of radiosonde humidity archives for climate studies. Bull. Amer. Meteor. Soc., 72, 1507-1520.

Enfield, D. B., 1996: Relationships of inter-American rainfall to tropical Atlantic and Pacific SST variability. Geophys. Res. Lett., 23, 3305-3308.

— fall on the interaction of the tropical Atlantic and Pacific Oceans. J. Climate, 12, 2093-2103.

— , and S.-K. Lee, 2005: The heat balance of the Western Hemisphere warm pool. J. Climate, 18, 2662-2681.

Gibson, J. K., P. Kallberg, S. Uppala, A. Hernandez, A. Nomura, and E. Serrano, 1997: ERA description. ECMWF ReAnalysis (ERA) Project Report Series 1, 72 pp.

Grist, J. P., and S. A. Josey, 2003: Inverse analysis adjustment of the SOC air-sea flux climatology using ocean heat transport constraints. J. Climate, 16, 3274-3295.

Hastenrath, S. L., 1966: The flux of atmospheric water vapor over the Caribbean Sea and the Gulf of Mexico. J. Appl. Meteor., 5, 778-788.
1978: On modes of tropical circulation and climate anomalies. J. Atmos. Sci., 35, 2222-2231.

Helfand, H. M., and S. D. Schubert, 1995: Climatology of the simulated Great Plains low-level jet and its contribution to the continental moisture budget of the United States. J. Climate, 8, 784-806.

Higgins, R. W., Y. Yao, E. S. Yarosh, J. E. Janowiak, and K. C. Mo, 1997: Influence of the Great Plains low-level jet on summertime precipitation and moisture transport over the central United States. J. Climate, 10, 481-507.

Hu, Q., and S. Feng, 2001: Climatic role of the southerly flow from the Gulf of Mexico in interannual variations in summer rainfall in the central United States. J. Climate, 14, 3156-3170.

Josey, S. A., E. C. Kent, and P. K. Taylor, 1998: The Southampton Oceanography Centre (SOC) Ocean-Atmosphere Heat, Momentum and Freshwater Flux Atlas. Southampton Oceanography Centre Rep. 6, 30 pp.

Kalnay, E., and Coauthors, 1996: The NCEP/NCAR 40-Year Reanalysis Project. Bull. Amer. Meteor. Soc., 77, 437-471.

Kanamitsu, M., W. Ebisuzaki, J. Woollen, S. K. Yang, J. J. Hnilo, M. Fiorino, and G. L. Potter, 2002: NCEP-DOE AMIP-II reanalysis (R-2). Bull. Amer. Meteor. Soc., 83, 1631-1643.

Kistler, R., and Coauthors, 2001: The NCEP-NCAR 50-year reanalysis: Monthly means CD-ROM and documentation. Bull. Amer. Meteor. Soc., 82, 247-267.

Knaff, J. A., 1997: Implications of summertime sea level pressure anomalies in the tropical Atlantic region. J. Climate, 10, 789804

Lee, S.-K., D. B. Enfield, and C. Wang, 2005: OGCM sensitivity experiments on the annual cycle of Western Hemisphere warm pool. J. Geophys. Res., in press.

Peixoto, J. P., and A. H. Oort, 1992: Physics of Climate. American Institute of Physics, 520 pp.

Rasmusson, E. M., 1967: Atmospheric water vapor transport and the water balance of North America: Part I. Characteristics of the water vapor flux field. Mon. Wea. Rev., 95, 403-426.

—, 1968: Atmospheric water vapor transport and the water balance of North America: Part II. Large-scale water balance investigations. Mon. Wea. Rev., 96, 720-734.

_ 1971: A study of the hydrology of eastern North America using atmospheric vapor flux data. Mon. Wea. Rev., 99, 119135.

Ruprecht, E., and T. Kahl, 2003: Investigation of the atmospheric water budget of the BALTEX area using NCEP/NCAR reanalysis data. Tellus, 55A, 426-437.

Schubert, S. D., H. M. Helfand, C. Y. Wu, and W. Min, 1998: Subseasonal variations in warm-season moisture transport and precipitation over the central and eastern United States. J. Climate, 11, 2530-2555.

Wang, C., and D. B. Enfield, 2001: The tropical Western Hemisphere warm pool. Geophys. Res. Lett., 28, 1635-1638.

_, and 2003: A further study of the tropical Western Hemisphere warm pool. J. Climate, 16, 1476-1493.

Xie, P., and P. A. Arkin, 1997: Global precipitation: A 17-year monthly analysis based on gauge observations, satellite estimates, and numerical model outputs. Bull. Amer. Meteor. Soc., 78, 2539-2558. 